\title{
Development of W-coating with functionally graded W/EUROFER-layers for protection of First-Wall materials
}

\author{
Karlsruhe Institute of Technology, Institute for Applied Materials - Materials and Biomechanics
}

${ }^{*}$ Forschungszentrum Jülich, Institute of Energy and Climate Research - Materials Synthesis and Processing

\begin{abstract}
Introduction
To protect First-Wall materials, e.g. reduced activation ferritic martensitic steels, against the plasma of future fusion reactors tungsten (W)-coatings are a feasible option. The difference in coefficient of thermal expansion (CTE) between the $W$ and the substrate can be compensated by functionally graded (FG)-layers in between. Such layer system, with stepwise graded FG-layers, were successfully produced by vacuum plasma spraying (VPS). The fabricated layer system have satisfactory interface toughness with the substrate at $550{ }^{\circ} \mathrm{C}$. Thermo-mechanical tests show that the layer systems can withstand thermal shocks of $0.19 \mathrm{GW} / \mathrm{m}^{2}$ and are resistant to thermal fatigue for at least 500 cycles between 350 and $550{ }^{\circ} \mathrm{C}$. Despite these advantages VPS reduces, however, the hardness of the substrate during coating.
\end{abstract}

\begin{tabular}{|c|c|c|c|c|}
\hline \multicolumn{5}{|c|}{$\begin{array}{l}\text { Interface toughness } \\
\text { Motivation and Objective } \\
\text { The substrate hardness loss, caused by VPS, can be moderated by } \\
\text { modified spraying parameters. Layer adhesion tests are performed to } \\
\text { investigate the effect of the modified parameters on the interface } \\
\text { toughness. }\end{array}$} \\
\hline $\begin{array}{c}\text { Layer } \\
\text { system }\end{array}$ & $\begin{array}{l}\text { Number } \\
\text { of layers: }\end{array}$ & $\begin{array}{l}\text { Nominal coating } \\
\text { thickness in um }\end{array}$ & Modification & $\begin{array}{c}\text { Substrate } \\
\text { hardness loss }\end{array}$ \\
\hline 1 & 4 & 1200 & & High \\
\hline 2 & 6 & 2000 & & High \\
\hline 3 & 1 & 700 & $\begin{array}{l}\text { Increased spraying } \\
\text { distance }\end{array}$ & None \\
\hline 4 & 1 & 700 & Reduced plasma current & High \\
\hline 5 & 1 & 700 & $\begin{array}{l}\text { Increased movement } \\
\text { speed } \\
\text { of spraying system }\end{array}$ & Moderate \\
\hline
\end{tabular}

Determination of interface toughness

- Four point bending testing technique $[4,5]$

- Specimens with notch and pre-crack up to coating/substrate interface

- Testing temperature: $550^{\circ} \mathrm{C}$

- Controlled constant displacement rate: $0.5 \mu \mathrm{m} / \mathrm{s}$

\section{Force-deflection curves}

- Plateau in curve

- Not visible for layer system 3 and reference EUROFER

- Decrease in secant stiffness due to layer delamination

- Layer delamination confirmed after testing

Calculating energy release rate $G$ - Force $P$ at start of delamination

- Layer residual stresses estimated by FE-simulations

- Comparable $\mathrm{G}$ calculated

\section{Layer adhesion}

- Fracture surfaces imply ductile fracture, layer system 3 only partially near crack tip

- Except for layer system 3, modified spraying parameters produce coatings with comparable interface toughness

\section{Outlook}

- Determine compromise of layer adhesion and hardness loss
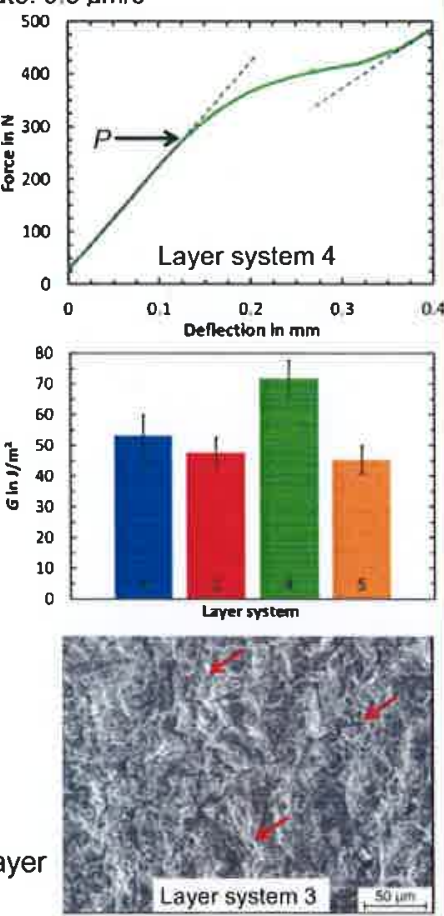

Simulation of Mock-up

Motivation and Objective

Based on the promising results at small scale the coatings are transferred to larger scale, with a Mock-Up as first upscaling step. Its behavior, after VPS and during operation, is estimated beforehand by finite element (FE)simulations in form of a sequential thermal-stress analysis.

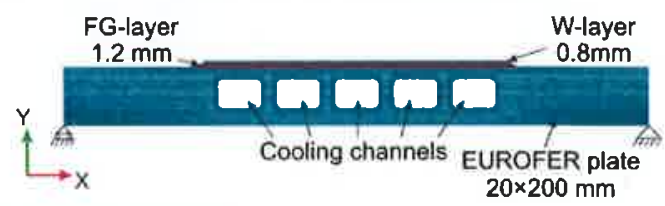

Parameter thermal analysis

-VPS: $\quad$ Layer system $750^{\circ} \mathrm{C}$

- Operation: $\quad$ W-surface $600^{\circ} \mathrm{C}$, cooling channels $320^{\circ} \mathrm{C}$

Parameter stress analysis

- End of VPS as initial stress free state

- Material behavior: W linear elastic, ideal plastic

EUROFER linear elastic, non-linear viscoplastic,

with isotropic hardening

FG-layer W-EUROFER linear interpolation

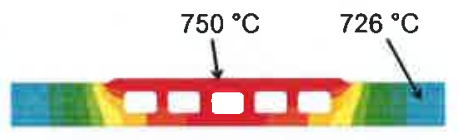

VPS temperature distribution

Simulated strains and stresses

- Difference in CTE causes residual stresses, deflection of the structure and plastic deformation

- Highest increase of plastic strain after VPS (Line 1)

- Additional plastic strain due to transformation of residual stresses (Line 2)

Influence of temperature loading - Simultaneous heating without intermediate steps leads to sequential in-/decrease of thermal strains

- Sequential in-/decrease cause thermal induced stresses and inelastic deformation

- Intermediate steps necessary during heating and cooling

\section{Outlook}

- Implement layer adhesion in simulation and increase number of simulated operation cycles

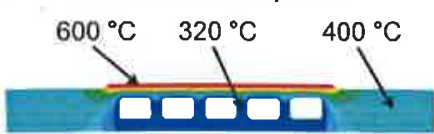

Operation temperature distribution
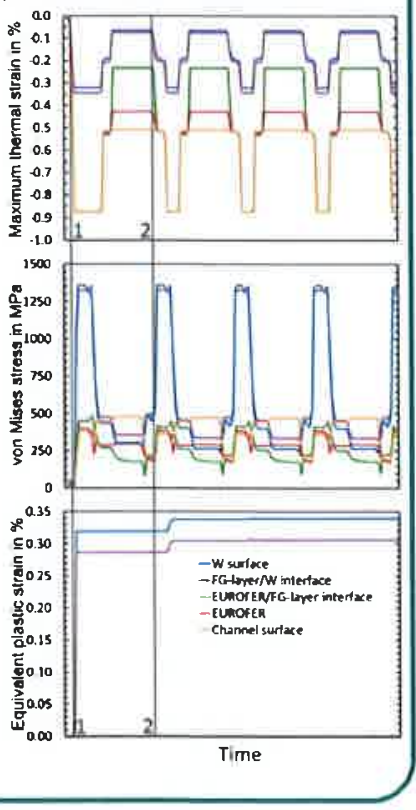

References

[1] DD Qu el al . Fusion Sci Technol 68 (3) (2015) 578-581.

(2) DD QU, PhD Thesis, Karlsuhthe, 2016

[4] P.G Charalembides, et al, J Appl Mech 56 (1) (1989) 77-82 